\title{
RECOGNITION OF JAPANESE KANJI AND HIRAKANA IN THE LEFT AND RIGHT VISUAL FIELDS
}

\author{
TAKESHI HATTA ${ }^{1}$
}

Osaka Lniversity of Education

\begin{abstract}
Two experiments were conducted concerning recognition of verbal material in Japanese. In Experiment I, single Kanji and Hirakana (corresponding to the used Kanji) were presented tachistoscopically to the left or right visual field. Kanji was recognized more accurately in the left visual field while Hirakana was recognized better in the right visual field. In a second experiment, Kanji words and mixed words (Kanji were mixed with Hirakana) were presented to either the left or the right visual field. The results indicate that Kanii has properties which are different from the other types of verbal materials and the direction of laterality differences for Kanji depends upon very different types of brain processing. Furthermore the results suggest the possibility of cultural differences betwcen Japanese and Westerners in hemispheric information processing systems.
\end{abstract}

Many tachistoscopic recognition experiments show a right visual field superiority for verbal materials and this has been interpreted in terms of functional hemispheric asymmetry (Mishkin \& Forgay, 1953; Bryden \& Rainey, 1963; Bryden, 1965; Kimura, 1966; Hatta, 1977a).

Several studies have reported on visual field differences with respect to verbal materials in Japanese orthography. Japanese orthography is peculiar in that three types of symbols, Katakana, Hirakana, and $K a n j i$ are used in combination. $K a$ takana and Hirakana are phonetic symbols for syllables as are the letters of the European alphabet for consonants and for vowels. Kanji are essentially non-phonetic logographic symbols or ideographs. There are about ten thousand Kanji in Japanese orthography but the minimal set of 1850 Kanji is adopted for standard use by the Japanese Ministry of Education.

With regard to the recognition of Japanese verbal materials, Hirata and Osaka

1 The author wishes to express his appreciation to Drs. D. J. Dimond, G. J. Harrison, and A. Beaton (Dept. Psychol. Univ. College, Cardiff, U.K.) for their critical reading of the manuscript and valuable comments.
(1967) reported that words in Katakana were recalled better in the right visual field than in the left visual field whether they were exposed unilaterally or bilaterally. Hatta (1976) also suggested a superior function of the left hemisphere for the perception of Hirakana letters in Japanese because the experimental condition where they were presented to the left visual field first and to the right visual field second produced more errors in matching judgements than the reverse order of presentation. These results with Japanese verbal materials accord with the finding from studies using verbal materials of Roman orthography.

Recently both Sasanuma, Itoh, Mori, and Kabayashi (1977) and Hatta (1977a, b) reported the results of tachistoscopic recognition experiments on Kanji materials presented in rapid succession. Sasanuma, et al. (1977) exposed tachistoscopically non-sense Hirakana and Kanji words in the right and left visual fields of normal righthanded subjects and found a significant right visual field superiority in non-sense Hirakana recognition and a non-significant trend towards the left visual fields superiority in randomly paired Kanji recognition. In Hatta's preliminary study 
(1977a), individual hanji were tachistoscopically presented to the right or left visual field and he found a highly significant left visual field superiority.

These results strongly suggest that Kana and Kanji processing call for different types of cognitive lunctions in the cerebral hemispheres. This suggestion is also raised in recent studies with Japanese aphasic patients. Sasanuma (1975) reported that the abilities of some Japanese aphasics to use Kana signs and Kanji characters can be selectively impaired and that their recovery processes also vary with aphasic types. Yamadori (1975) also found a case of alexia with agraphia in a Japanese patient who can read words composed of logograms (Kanji), but who cannot read words composed of phonograms (Kana). These results suggest the possibility that different types of symbols are differentially processed by the two halves of the brain.

Thus the purpose of the first experiment in this study was to demonstrate lateral differences in performance level when hana and Kanji were tachistoscopically exposed to the right and left visual fields of normal subjects.

In this experiment (unlike that of Sasanuma, et al. (1977) who used non-sense hanji), single Kanji and Hirakana were used as stimuli in each trial because the intrinsic nature of Kanji (non-phonetic logograph) might be reduced in the case of random pairing and in ordinary Japanese orthography. Kiatakana are used only in the case of transcription of adopted words.

\section{EXPERIMENT I}

\section{Method}

Subjects. The subjects were 15 male and 15 female students, ranging from 19 to 23 years old, at the Osaka University of Education. All subjects filled in the Hatta and Nakatsuka Handedness inventory (Hatta \& Nakatsuka, 1975) before the experiment. They were all right-handcd on the basis of this inventory. All subjects had normal or corrected-to-normal vision.

Apparalus and stimulus materials. A threcchannel projector tachistoscope which consisted of Kodak Ektagraphic projectors and Gerbrand G-1165 shutters were used.

For Kanji task, a set of 40 single Kanji were selected from Kitao's Kanji List (Kitao, Hatta, Ishida, Babazono, \& Kondo, 1977) for their high familiarity, concreteness and hieroglyphicity. These Kanji were taken from the 881 $K a n j i$ list for the standard use of primary school children by the Ministry of Education. Individual Kanji were presented in both visual fields. All Kanji were drawn in the Min-era type of print.

For the Hirakana task, a set of 40 Hirakana pairs were used. The Kun-Yomi or On-Yomi transcription of Kanji stimuli were used as Hirakana stimuli. In Japanese there are two possible acoustic renderings of Kanji. The Onromi or Sino-Japanese rendering derives from the Chincse pronounciation of the characters at the time of thcir first bcing used in Japan. The fiun-romi rendering is a native Japanese one. The rendering employed in the present study was selected by referring to the frequency of usage of each Kanji. Then among $40 \mathrm{Hira}$ hana stimulus sets, six stimuli consisted of one Hirakana letter, 27 of two letters and seven of thrce letters. Hirakana letters were vertically arranged and printed in black Letraset No. JPN 1512. Arabic numerals from two to nine were also used as stimuli in order to assure adequate control for eye fixation.

Each stimulus of Kanji, Hirakana and numeral was pasted upon white paper, and a slide made of each one. The stimuli were backprojected onto a translucent screen $100 \mathrm{~cm}$ in front of the subject at eye level. The Kanji stimuli appeared in black $4.01^{\circ}$ of visual angle right or left from the center of the screen, subtending a visual angle $1.49^{\circ}$. The Hirakana stimuli (one, two and three letters) appeared $4.01^{\circ}$ to the right or left of the fixation, subtending (respectively) a vertical angle of $0.97^{\circ}$, $2.58^{\circ}$, and $3.44^{\circ}$. The fixation digit subtended a visual angle of $0.57^{\circ}$. The whole visual field 
subtended a visual angle of $16.62^{\circ}$ vertically and of $24.06^{\circ}$ horizontally. The luminance of the screen was $49.32 \mathrm{~mL}(156.97 \mathrm{~cd} / \mathrm{m})$. Figure 1 shows an example of Kanji and Hirakana used in the experiment.

Procedure. Each subject attended two sessions: One for the Kanji task and one for the Hirakana task. These were on different days separated by two to five days. The order of the two tasks was counterbalanced across the subjects. Each session consisted of a practice session of 20 trials, followed by the test session.

The subject sat at a table, and his head was located on a chin-rest in front of the screen. For each trial, the subject was first asked to fixate on a small circle ( $0.83^{\circ}$ of visual angle), presented as a preparatory signal exposed for 2 sec in the center of the lighted screen. Then one Kanji and one numeral were simultaneously displayed for $20 \mathrm{msec}$. The exposure duration of Hirakana was also $20 \mathrm{msec}$. During the intertrial interval of $20 \mathrm{sec}$, the screen was filled by a blank white slide. Two seconds before cach exposure of the fixation circle, the experimenter said "focus" as a preparatory instruction. In adiance of a practice session five trials with a slide having only a numeral as the fixation point were given to subjects accustomed to the procedure. The task of the subject firstly was to report which number appeared at the focus point and then which
TABLE I

Mean percent correct recognition in the right and left visual fields for the Kanji and Hirakana tasks

\begin{tabular}{c|c|c}
\hline Task & Right visual field & Left visual field \\
\hline Kanji & $69.7 \%$ & $81.5 \%$ \\
Hirakana & $(S D=10.6)$ & $(S D=8.6)$ \\
& $(S D=4 \%$ & $60.1 \%$ \\
& & $(S D=9.3)$
\end{tabular}

Kanji or Hirakana was presented either on the left or the right side of the screen. Subjects were never informed of whether their responses were correct. In both test sessions for Kanji and Hirakana, 80 stimuli were presented to each subject allowing a total of 40 possible responses in each visual field. The order of presentation to each visual field was randomized. Scores for each subject were the number of correct letter identification in each visual field. Responses without correct identification of numbers at the fixation point were omitted from analysis.

\section{Resulls}

The mean percentage of correct recognition in the right and left visual fields for Kanji and Hirakana tasks are shown in Table 1. Examination of Table 1 indicates that the performance of the subjects

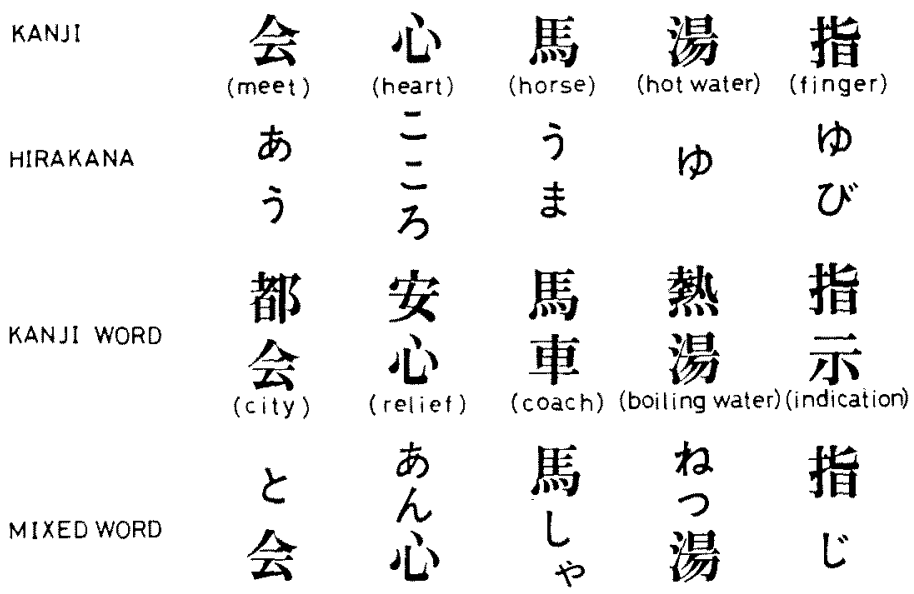

Fro. 1. Some samples of the stimulus materials used in the Experiment I and II. 
on the Kanji task showed a significant left visual field superiority $(t=6.77, d f=$ $29, p<.001)$, whereas a significant right visual field superiority on the Hirakana task is shown $(t=8.21, d f=29, p<.001)$. On the Kanji task, out of 30 subjects, 26 obtained higher scores for the left visual field, while only two obtained higher scores for the right visual field (two obtained nearly equal scores for both fields). On the other hand, out of 30 subjects, 28 obtained higher scores for the right visual field while only one obtained higher scores for the left visual field on the Hirakana task (one obtained equal scores for both fields). There was no significant sex difference for lateral differences in either task.

The literature previously describing a left visual field superiority for Kanji recognition was confirmed. However, when Kanji had been transcribed in Hirakana letters, the subjects recognized them more accurately in the right visual field. A significant right visual field superiority for the recognition of Hirakana letters is consistant with the results of the studies which employed alphabetical letters as verbal stimulus materials (Bryden \& Rainey, 1963; Bryden, 1965; Kimura, 1966; Fontenot \& Benton, 1972) as well as the studies in Japanese with one-Hirakana letter (Hatta, 1976), two-Hirakana letters (Sasanuma, et al., 1977), two-Katakana letters (Hirata \& Osaka, 1967).

All of these results can be interpreted as confirming a cerebral dominance of the left hemisphere for processing verbal materials.

A significant left visual field superiority for single Kanji recognition is consistent with the results of the previous studies by Hatta (1977a, b) and Sasanuma (1977). Hatta (1977a) reported that when high familiarity and low familiarity single $K a$ nji was presented tachistoscopically to the right or the left visual field, the subjects recognized more items correctly in the left visual field irrespective of their familiarity. A similar experiment (Hatta, 1977b) also reported left visual field superiority for the recognition of both abstract and concrete single Kanji. Recently, Sasanuma, et al., (1977) showed a trend towards left visual field superiority for recognition of randomly paired Kanji, although the difference was not significant.

These findings of lateralization in the opposite direction between Kanji and Hirakana suggest that the hemisphere processing involved in Kanji recognition is different from that for the recognition of $\mathrm{Hi}$ rakana and Katakana.

Studies of Japanese aphasic patients seem to support this hypothesis. Yamadori (1975) reported a case of alexia with agraphia. The patient when presented with a daily newspaper could not read Hirakana and Katakana letters but reading ability of Kanji was preserved. The patient would read the Kanji part but disregarded the remainder of the sentence. Sasanuma (1975) also reported a longitudinal study of a number of aphasic patients who exhibited selective impairment for Hirakana and Katakana letters whilst the ability to process Kanji was well preserved. Other patients showed selective impairment of Kanji with remarkable preservation of Hirakana and Katakana. The recovery processes are also different depending upon the type of aphasia.

Studies with normal subjects therefore and the studies with aphasic patients suggest that recognition of $K a n j i$ and the other materials in Japanese orthography represent distinctively different models which themselves call for different types of cognitive function in the two hemispheres.

Based on these data one may speculate on the nature of the cognitive processes involved in Kanji recognition. As shown in Fig. 1, Kanji possesses more highly organized and distinctive graphic patterns rather than Hirakana and Katakana. This feature makes it a good candidate for direct visual mapping or for a wholistic type of processing (Cohen, 1973; Patterson \& 
Bradshaw, 1975). The Kanji in this experiment were of high hieroglyphic value as rated by Kitao, et al., (1977), and most of these Kanji were derived initially from the shape of concrete objects and have subsequently evolved to the present form. In school, children begin by learning ha$n j i$, and most Japanese know them well. The Kanji used may easily correspond to concrete shapes and objects, and in this case a single $K a n j i$ in the left visual field should be recognized more accurately than that in the right visual field. On the other hand, the graphic representation of each Kanji is associated with both an inherent meaning and a phonological representation. Eventually, some kind of phonological activity may accompany the processing of Kanji. Thus, one may expect that the processing of Kanji can differ depending upon the degree of contribution of either the visual or phonological component.

\section{EXPERIMENT II}

As mentioned in Experiment I, Kanji characters have both visual and phonological aspects. Thus, it would be expected that either aspect of Kanji may be exploited to different degrees depending upon the specific type of processing required in a given situation. In other words, it would be expected that in the recognition of Kanji in which more of a phonological strategy than a visual strategy is called for, a right visual field superiority would be found; furthermore, on the task in which more of a visual strategy is demanded than a phonological strategy, a left visual field superiority would be extracted. To test this expectation, Kanji compound words (Kanji words) consisting of two letters and compound words of Kanji mixed with Hirakana (Mixed words) were employed in this experiment.

Kanji words were regarded as stimulus materials which depend more upon the visual type of strategy than the phonological type of strategy in processing. This view is held because the visual aspect of each Kanji are seen as combining to give the word which the Kanji make up. On the other hand, Mixed words were presumed to be stimulus materials dependent on a phonological strategy rather than a visual strategy. This view is held because the phonological aspect which single Kanji inherently possesses is likely to be assimilated to the necessarily phonological material that the Hirakana stimuli present.

\section{Method}

Subjects. Thirty right-handed students (15 male and 15 female) participated in the experiment. They all met the criteria adopted in the first experiment.

Apparalus and stimuli. The apparatus used was identical with that in Experiment $I$.

For the Kanji task, a set of 40 Kanji-words pairs were used. The Kanji words were used in both visual fields. The Kanji words consisted of two-character Kanji words, one of the two-character Kanji was identical with those Kanji used in the previous experiment. The two-character Kanji word was arrange vertically. The Kanji used in Experiment I occupied an upper part of two-character words for the half of the stimuli and occupied a lower part for the remainder of the stimuli. These twocharacter Kanji words were all highly familiar ones which are commonly used in a primary school reading text.

Each of the Kanji pairs and arabic numerals from tow to nine were combined and used as the stimuli. These were rear-projected onto a translucent screen as described in Experiment I. The Kanji stimuli appeared in black $4.01^{\circ}$ right or left from the center of the screen, which subtended a visual angle of $2.97^{\circ}$ vertically and $0.97^{\circ}$ horizontally. In the Mixed words task, a set of 40 stimuli which consisted of a single Kanji and Hirakana letters were used. They were all vertically arranged. The Kanji used were identical with those in Experiment I. The Hirakana letters were those which correspond to the Kanji added as Kanji words stimuli 
in this experiment. The Kanji which were identical with those in Experiment 1 appeared in the upper part of the stimuli on half of the trials and appeared in the lower part of the stimuli on the other half of the trials. Hirakana as a part of these Mixed words stimuli consisted of one, two or three letters. The Mixed words and numeral were paired and made into slides. The Mixed word stimuli appeared in black on a translucent screen $4.01^{\circ}$ off to the right or left from the center of the screen. They subtended a vertical visual angle of $0.97^{\circ}$ (one Hirakana letter), $2.58^{\circ}$ (two Hirakana letters), and $3.44^{\circ}$ (three Hirakana letters) and a horizontal visual angle of $0.97^{\circ}$. The fixation digit subtended a visual angle of $0.57^{\circ}$. The visual angle of the whole visual field and luminance of the screen were identical with Experiment I. All Kanji characters were drawn in Min-era print. Fig. I shows an example of Kanji words and Mixed words in the present experiment.

Procedure. The general procedures were identical with those of Experiment I except that the stimulus exposure duration was 25 msec.

Each subject was given two separate sessions of the task for Kanji words and Mixed words on different days. The order of the two tasks was counterbalanced across the subjects. In each session, the subjects attended a practice session of 20 trials followed by test sessions. The task of the subjects was to report the central digit exposed at the center of the screen firstly and to report what kanji words or Mixed words appeared either on the left or the right visual field. In each session, the total of 80 stimuli were presented to each subject allowing a total of 40 possible responses in each visual field. Scores for each subject were the number of correct whole-word identifications. Responses where correct report of the central digit was absent were omitted from analysis. This occurred on less than $2.5 \%$ of all trials.

\section{Results}

The mean percentage of correct identification in the right and left visual fields for Kanji words and Mixed words are presented in Table 2. It is shown that the
TABLe 2

Mean percent correct recognition in the right and left visual fields for the Kanji word and Mixed word tasks

\begin{tabular}{c|c|c}
\hline Task & Right visual field & Left visual field \\
\hline \multirow{3}{*}{ Kanji word } & $64.23 \%$ & $57.82 \%$ \\
& $(S D=16.29)$ & $(S D=16.18)$ \\
Mixed word & $67.06 \%$ & $56.97 \%$ \\
& $(S D=16.14)$ & $(S D=16.71)$
\end{tabular}

performance of the subjects both on the Kanji words and on the Mixed words showed a significant right visual field superiority $(l=3.46, t=4.27, d f=29, \quad p<$ 0.01 ). On Kanji words, out of 30 subjects, 22 obtained higher scores for the right visual field, while seven obtained higher scores for the left visual field (one showed equal scores for both visual fields). And on the Mixed words task, out of 30 subjects, only one showed higher scores for the left visual field, while 28 subjects obtained higher scores for the right visual field, and one subject showed equal scores for both visual fields.

\section{Discussion}

For both, kanji words and Mixed words, a right visual field superiority was found. The direction of this laterality difference is not identical with the ranji recognition task, but with the Hirakana letter recognition task of the previous experiment.

The hypothesis was as follows:

1. In Kanji words recognition, the subjects would show a superior recognition in the left visual field, because visual type of strategy or processing is called for as in the single Kanji recognition task.

2. On the other hand, in the Mixed words recognition task, it would be expected that a right visual field superiority exists because the phonological type of processing strategy is called for than visual type of processing strategy as in the Hirakana letters recognition.

As shown in Table 2, the second hy- 
pothesis was supported, but the results of the present expcriment were opposed 10 the first hypothesis. In the Mixed words task, the stimulus materials consisted of a single Kanji and Hirakana letters, In $\mathrm{Hi}$ rakana letter recognition, several studies have already demonstrated a right visual field superiority (Hatta, 1976; Sasanuma, et al., 1977) while a left visual field superiority for single Kanji recognition was demonstrated in Experiment $I$ and in the previous studies (Hatta 1977a, b). It appears that these results imply that Kanji recognition requires a specialized process of the left hemisphere in Japanese subjects. The Mixed words task might be regarded as presenting competing cues for phonological or for visual processing. From this point of view, the present results indicate what happens when there is competition between two different types of processing. That is with Hirakana processing (phonological) which favours the left hemisphere overwhelms Kanji processing (visual) which favours the right hemisphere. The stimulus materials of the present experiment consisted of mixed characters; the Hirakana letters component occupied much of the whole stimulus. This may be a further reason for a left hemisphere superiority.

For recognition of Kanji words, a left visual field superiority was expected following the hypothesis mentioned previously. The left visual field superiority for the recognition of a single Kanji, found in the first experiment, may be strengthened when two Kanji are used as stimuli. Thus an exaggerated left visual field superiority was anticipated. Nevertheless, the present results showed a right visual field superiority. Because of the combining of two Kanji characters, the trait which a single Kanji inherently possesses in favour of the right hemisphere (visual) processing, is apparently reduced. Instead, the left hemisphere function again becomes dominant as if the phonological aspects of Kanji become emphasized. It must be borne in mind that with the Kanji words, which added another Kanji to the original Kiamji used in Experiment I, the individual and multiple readings of single lianji are reduced to a single acoustic rendering. Becatse of this reduction, the phonological processing might become an optimal strategy and so left hemisphere dominance is again found. In other words, in single Kanji recognition, when multiple reading of Kanji are possible, visual processing rather than phonological is employed. On the other hand when only a single rendering of the combined Kanji is available, phonological rather than visual processing is adopted. According to this hypothesis, it follows that the single Kanji task is achieved visually and Kanji words and Mixed words tasks phonologically.

Further, the case of the task randomly paired Kanji of Sasanuma, et al. (1977) might now be regarded as an intermediate situation. In their task, subjects would have more scope to search for some suitable strategy of their own in recognizing the stimuli. For some subjects then phonological processing might be employed and for some other subjects who processed the items of a non-coherent kanji pair separately, visual proceedings might be favoured. That is, the non-sense configuration of the Kanji pairs of Sasanuma, et al. would not uniformly lead to phonologically based processing.

These results indicated as mentioned earlier, that Kanji have two different types of components, visual and phonological, and which component is exploited is due to the specific type of processing required in a particular task. And the visual component which is dominant in the case of single $K a n j i$ is cancelled or overwhelmed by the other type of component when some other letters, even of Kanji are added.

\section{General Discussion}

Two experiments on perceptual asymmetry for Japanese Kanji recognition were 
conducted. These experiments suggest that the direction of laterality differences of Kanji was dependent upon the types of processing required in a given situation. That is to say, in a single Kanji recognition task, Kanji were recognized more accurately from the left visual field (see Table 1) but once some other verbal materials of the same kind were added to single Kanji, Kanji were recognized more accurately from the right visual field (see Table 2).

These results indicate that the Kanji have properties which are essentially different from other types of verbal materials, such as Hirakana and Katakana in Japanese orthography and the Alphabet in Roman orthography.

Recently, Hokkyo (1976) proposed a hypothesis that in Japanese people phonetic symbols (Hirakana and Katakana) are recognized in the left hemisphere and logographic symbols (Kanji) are recognized in the right hemisphere. It appears that the present results on different kinds of Kanji recognition tasks do not support this hypothesis except in the case of a single Kanji recognition task. The present results rather suggest that Kanji recognition in Japanese are more fluid and less rigid than suggested by Hokkyo (1976).
As mentioned earlier, Kanji possesses a "visual" component. Kanji are logographic symbols which represent lexical morphemes. But this essential attribute of Kanji is coupled with highly organized and difinite graphic quality. Some types of Kanji were derived from the shapes of concrete objects, and they have been modified into the present forms as shown in Fig. 2. This attribute of Kanji may be strongly reflected in single Kanji recognition, and thus a left visual field superiority is produced similar to the case of nonverbal materials (Kimura, 1966, 1969).

Whilst Kanji is associated not only with meaning but also with one or several phonological representations, some kind of phonological activities may positively accompany the Kanji processing. Thus, when some other phonological component of each Kanji (inherent to each Kanji), could be extracted this would be conductive to a right visual field superiority. The result of the second experiment in this study and the results of a random paired hanji recognition task in Sasanuma's study, seem to confirm this interpretation.

At any rate, the present results strongly indicate that Kanji are quite unique symbols compared with alphabetical symbols, and Japanese people need the integrated

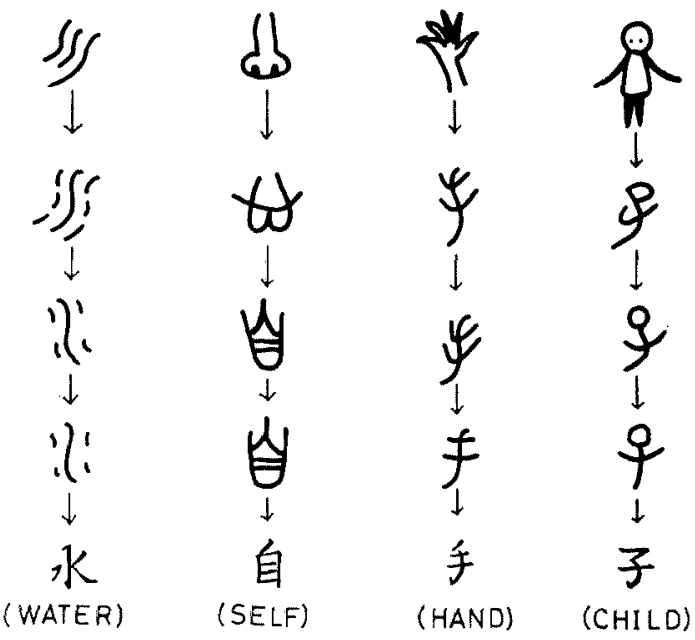

FIG. 2. The modification processes of Japanese Kanji. 
action of both hemisphere processing systems in reading their texts; to a far greater extent that would the Westerner in reading his language.

Recently, Tsunoda (1975, 1977) suggested cross-cultural differences concerning a hemisphere dominance of auditory recognition. Tsunoda reported that animal sounds such as the song of a bird, a dog barking, mewing, croaking and chirping of a cricket were recognized dominantly in the left hemisphere in Japanese people, while for the Westerner, these sounds were recognized dominantly in the right hemisphere as well as other noises. This suggestion in addition to the present results on the recognition of Kanji strongly suggest that the verbal vs. nonverbal distinction in lateral differences in recognition may be less important in Japanese people.

\section{REFERENCES}

Bryden, M. P. 1965 Tachistoscopic recognition, handedness, and cerebral dominance. Neuropsychologia, 3, 1-8.

Bryden, M.P., \& Ratney, C. A. 1963 Leftright differences in Tachistoscopic recognition. Journal of Experimental Psychology, 66, 568-571.

Cohen, G. 1973 Hemisphere differences in serial vs. parallel processing. Journal of Experimental Psychology, 97, 349-356.

Fontenot, D. J., \& Benton, A. L. 1972 Perception of direction in the right and left visual fields. Neuropsychologia, 10, 447-452.

Hatra, T. 1976 Asynchrony of lateral onset as a factor in difference in visual field. Perceptual and Motor Skills, 42, 163-166.

Hatta, T. 1977a Recognition of Japanese Kan$j i$ in the left and right visual fields. Neuropsychologia, 15, 685-688.

HATTA, T. $1977 \mathrm{~b}$ Lateral recognition of abstract and concrete Kanji in Japanese. Perceptual and Motor Skills, 45, 731-734.
Hatta, T., \& Nakatsuka, Z. 1975 H. N. Handedness inventory. In S. Ono (Ed.), Papers in celebration of 63 rd birthday of Prof. $K$. Olmishi, Osaka City University. Pp. 224-247.

Hirata, K., \& Osaka, R. 1967 Tachistoscopic recognition of Japanese letter materials in left and right visual fields. Psychologia, 10, 718.

Hоккуо, N. 1976 Hemisphere asymmetry and dream. Mathematical Science, 154, 66-68.

KimurA, D. 1966 Dual functional asymmetry of the brain in visual perception. Neuropsychologia, 4, 275-285.

Kimura, D. 1969 Spatial localization in left and right visual fields. Canadian Journal of Psychology, 23, 445-458.

Krtao, N., Hatta, T., Ishida, M., Babazono, Y., \& Kondo, Y. 1977 Concreteness, hierglyphicity and familiarity of the Kanjis. Japanese Journal of Psychology, 48, 105-111. (In Japanese with English Summary)

Mishikin, M., \& Forgay, D. G. 1953 Word recognition as a function of retinal locus. Journal of Experimental Psychology, 43, 43-48.

Patterson, K., \& Bradshaw, J. L. 1975 Differential hemispheric mediation of nonverbal visual stimuli. Journal of Experimental Psychology: Human perception and performance, $\mathbf{1}$, 246-252.

SAsanuma, S. 1975 Kana and Kanji processing in Japanese aphasica. Brain and Language, 2, 369-383.

Sasanuma, S., Itoh, M., Mori, K., \& Kabayashi, Y. 1977 Tachistoscopic recognition of Kana and Kanji words. Neuropsychologia, 15, 547 553.

Tsunoda, T. 1975 Functional differences between right and left-cerebral hemispheres detected by the key-tapping method. Brain and Language. 2, 152-170.

TsunodA, T. 1977 Brain and language 1977. In T. Tsunoda, Y. Tanaka, S. Omori, \& N. Sawada (Eds.), Language, consciousness and life. Kyoritsu-shuppan. Pp. 1-31.

YAMAdOR, A. 1975 Ideogram reading in Alexia. Brain, 98, 231-238.

(Received Jan. 9, 1978) 